\title{
Prevalence and cardiometabolic associations of the glucocorticoid receptor gene polymorphisms N363S and Bcll in obese and non-obese black and white Mississippians
}

\author{
Eugen Melcescu, ${ }^{1}$ Michael Griswold, ${ }^{2}$ Lianbin Xiang, ${ }^{3}$ Sheila Belk, ${ }^{3}$ \\ Denise Montgomery, ${ }^{3}$ Marilyn Bray, ${ }^{4}$ Kevin S. Del Ben, ${ }^{3}$ Gabriel I. Uwaifo, ${ }^{1,5}$ \\ Gailen D. Marshall, ${ }^{3}$ Christian A. Koch ${ }^{1,6}$
}

${ }^{1}$ Division of Endocrinology, University of Mississippi School of Medicine; ${ }^{2}$ Center of Biostatistics and Bioinformatics; ${ }^{3}$ Division of Allergy and Clinical Immunology; ${ }^{4}$ Department of Pathology, University of Mississippi School of Medicine, Jackson, MS; ${ }^{5}$ Division of Endocrinology, Louisiana State University Health Sciences Center, New Orleans, LA; ${ }^{6}$ Medical Service, G.V. (Sonny) Montgomery VA Medical Center, Jackson, MS, USA

\begin{abstract}
OBJECTIVE: Polymorphisms (SNP) in the glucocorticoid receptor (GR) gene can alter sensitivity to glucocorticoids. Previous studies of the N363S and BclI SNP in the GR gene have shown a metabolic syndrome phenotype in mostly non-African populations. The obesity phenotype of African Americans (AA) seems to be more severe than that of Caucasians. DESIGN: We aimed to assess the prevalence of $\mathbf{N 3 6 3 S}$ and $B c l I$ in obese and non-obese Caucasian $(n=26)$ and African $(n=23)$ Mississippians (age: 23-63 years) to investigate associations with body composition (body mass index/BMI, waist-to-hip ratio), metabolic parameters (salivary cortisol, fasting glucose and insulin, hemoglobin A1C, fructosamine, HOMA-IR index), and psychological stress perception (blood pressure/BP, perceived stress scale/PSS). RESULTS: All subjects were homozygous for wildtype N363N. BclI polymorphism genotype frequencies among the 23 AA were: homozygous CC (57\%), GG (4\%), and heterozygous CG (39\%), and among the 26 white women: homozygous CC (35\%), GG (19\%), and heterozygous CG (46\%). Linear and logistic regression analyses including a parsimonious model identified BMI as a statistically significant parameter between the two ethnic groups (BMI was $3.13 \mathrm{~kg} / \mathrm{m}^{2}$ higher in AA). Within the AA group, BMI, waist-to-hip ratio, log (HOMA-IR), PSS scores, BP, and hyperlipidemia showed no statistically significant relationships for the $B c l$ I polymorphism. PSS scores were 15.2 for AA vs. 14.7 for white women (normal mean: 14.7 vs. 12.8). CONCLUSION: Black Mississippians
\end{abstract}

Prof. Dr. med. habil. Christian A. Koch, Director, Division of Endocrinology, Head, Endocrine Tumor Programme, University of Mississippi Medical Center, 2500 N. State Str., Jackson, MS 39216, USA, Tel.: 601-984-5495, Fax: 601-984-5789, E-mail: ckoch@umc. edu or christian_albert_koch@yahoo.com

Received 18-01-12, Revised 02-03-12, Accepted 01-04-12 
have a higher BMI than whites, which may be related to the presence of the $B c l$ I polymorphism and increased glucocorticoid sensitivity. Although more blacks (52\%) than whites $(38 \%)$ had elevated BP, PSS scores in both groups suggest that a high BMI is not regarded as abnormal or stressful. This might negatively impact behavior change regarding lifestyle modifications with increased physical activity and healthier food choices. Larger studies, particularly in African populations, are needed to better define metabolic and psychological characteristics in relation to the $\mathbf{N 3 6 3 S}$ and $B c l$ I GR gene polymorphisms.

Key words: Glucocorticoid receptor, Polymorphism, BclI, Diabetes, Stress, Body mass index, Waist circumference, Obesity

\section{INTRODUCTION}

Obesity, which occurs when more calories are consumed than burned over time, has become an epidemic in the United States. According to recent data (the 2007-2008 National Health and Nutrition Examination Survey which actually collects measured and not self-reported heights and weights) from the Centers for Disease Control (CDC) and Prevention, approximately $36 \%$ of women are obese and an estimated $17 \%$ of American children aged 2-19 years are overweight or obese. In Mississippi, approx. 34\% of the population is overweight and another $34 \%$ are obese, leaving $32 \%$ of Mississippians having normal body weight, as defined by the body mass index (BMI). ${ }^{1,2}$ Obesity is a risk factor for developing type 2 diabetes and nearly 26 million children and adults in the U.S. have diabetes with another estimated 79 million Americans having prediabetes and therefore being at risk for developing type 2 diabetes. National healthcare spending, including medical bills of an obese individual, is $42 \%$ higher than that of someone who is not obese according to CDC data. In 2011, Gallup's annual health and healthcare survey found American men were on average $15 \mathrm{lbs}$ over their ideal weight and American women were $22 \mathrm{lbs}$ over their ideal weight. The cost of caring for someone with diabetes is $\$ 1$ out of every $\$ 5$ in total healthcare costs according to the American Diabetes Association. Obesity is not only very prevalent in the U.S. but also worldwide, with variable rates in European countries and sociodemographic, environmental, ethnic, and dietary factors playing a major role. ${ }^{3-12}$

About $40-80 \%$ of the variation in obesity has been linked to genetic factors. Analyzing the human genome for possible gene variants associated with obesity led to the discovery of major obesity loci on chromosomes 2, 5, 10, 11, 16, and 20. ${ }^{13-18}$ Differential polygenic predispositions across ethnicities could therefore explain differential development of obesity and other disease states.

The frequency of such SNPs varies greatly among ethnic populations and the effects of these polymorphisms may differ among races related to different combinations of polymorphisms of several genes and their protein interactions and differences in environmental and socioeconomic factors. ${ }^{19,20}$ The obesity phenotype of African Americans seems to be more severe than that of Caucasians. We here examined whether glucocorticoid receptor polymorphisms (SNP) mediated this ethnicity-obesity relationship. SNPs of the GR may play a role in aggravating the course of certain diseases. Some of these conditions are listed in Table 1.

Cortisol is a stress hormone associated with various disease states including obesity. ${ }^{3,4,28}$ Glucocorticoid sensitivities vary greatly between individuals and may help explain why individuals respond differently to the

Table 1. Role of GR gene polymorphisms in various diseases

- progression of lung disease in young patients with cystic fibrosis ${ }^{21}$

- increased disease activity in inflammatory bowel diseases ${ }^{22}$

- reduced susceptibility to develop rheumatoid arthritis ${ }^{23}$

- avascular necrosis of the femoral head ${ }^{24}$

- decreased bone mineral density in patients with endogenous hypercortisolism ${ }^{25}$

- susceptibility to develop major depression ${ }^{26}$

- increased risk for impaired endothelial function ${ }^{27}$ 
same amount of glucocorticoid. ${ }^{29,30}$ The best known polymorphisms in the GR gene related to an altered GC sensitivity are: ER22/23EK, N363S, and BclI and TthIIII restriction fragment length polymorphisms. At present, data regarding their effect on cardiovascular risk factors, body composition, metabolic parameters, and psychological stress are mixed. ${ }^{31-35}$ This may in part be related to the respective ethnic group studied, including mostly Caucasians (French, Swedish, Dutch, Anglo-Celtics, Northern Europeans, Hungarians) but also Indians, Middle Eastern, Asians, Vietnamese, and Koreans. Recently, a heterozygous nucleotide substitution in exon 2 of the GR, the D401H mutation, has been found to potentially predispose Colombians to obesity, hypertension, and other manifestations of the metabolic syndrome..$^{29}$ Our study population consisting of black and white Mississippians was designed to examine whether possible associations between N363S and BclI polymorphisms and various obesity-related clinical parameters help explain the associations previously observed between ethnicity and clinical parameters.

\section{SUBJECTS AND METHODS}

\section{Study design and data collection}

This study was conducted in accordance with the declaration of Helsinki and approved by the Institutional Review Board of the University of Mississippi Medical Center. All study subjects signed the informed consent. Our main objectives were to assess the prevalence of polymorphisms N363S and BclI in the glucocorticoid receptor gene in obese and non-obese Caucasian and African American (AA) individuals from Jackson, Mississippi, and to investigate associations with body composition, metabolic parameters, and psychological stress measures. All of our study participants were women. All participants perceived themselves as healthy. The age range was 24-63 years overall (32-58 yrs for AA, 24-63 yrs for white women).

We analyzed two distinct ethnic groups: (1) obese and non-obese Caucasian females $(\mathrm{N}=26)$ and (2) obese and non-obese AA females $(\mathrm{N}=23)$. After informed consent, venous blood was drawn to obtain 20 cc EDTA blood to extract genomic DNA for SNP analyses. Obesity was defined as a BMI $>30$.

Glycemic control was assessed by measuring fast- ing glucose (in $\mathrm{mg} / \mathrm{dl}$ ) and insulin (in microIU $/ \mathrm{ml}$ ), hemoglobin $\mathrm{A} 1 \mathrm{C}$, and fructosamine (micromol/L) levels. HOMA-IR index was computed adjusting for glucose values in $\mathrm{mg} \%$. We additionally collected BMI, waist-to-hip ratio, systolic and diastolic blood pressure. Morning cortisol levels were obtained by collecting saliva at $8 \mathrm{AM}$ measured in our laboratory in $\mathrm{mcg} / \mathrm{dl}$ and converted to $\mathrm{ng} / \mathrm{dl}$ (normal, 100-750 ng/ dl, 7AM-9AM, Mayo Clinic Laboratories). To measure the perception of stress, we used the perceived stress scale (PSS). ${ }^{37}$

We compared the homozygous and heterozygous genotypes between Caucasian and African American female differences in relation to the aforementioned clinical parameters. In addition to this analysis, we performed a separate evaluation of the impact of CC (homozygous) and CG (heterozygous) genotypes on our study parameters within the AA group (group 2).

\section{Genetic analysis}

\section{Allelic Discrimination Assays for the GR BclI and N363S Polymorphism}

DNA was extracted using the commercial Puregene DNA Isolation Kit (Centra Systems) and 15 ng of DNA was used in each genotyping assay. The BclI (rs41423247) and N363S (rs6195) polymorphisms of the GR gene were detected by using the Applied Biosystems 7300 Real-Time PCR System with TaqMan SNP assay reagents and genotyping analyzed by SDS 2.1 package (Applied Biosystems). The sequences of probes were 5'-FAM-TCTGCTGATCAATCT-3' and 5'-VIC-TCTGCTGATGAATCT-3' for BclI and 5'-FAM-CTATTCCAATTTTCGGAACCA-3' and 5'-VIC-CTATTCCAACTTTCGGAACCA-3' for N363S. Reaction components and amplification parameters were based on the manufacturer's instructions using an annealing temperature of $60^{\circ} \mathrm{C}$ and optimized concentrations for primers and probes of $400 \mathrm{nmol} / \mathrm{l}$ and $50 \mathrm{nmol} / \mathrm{l}$, respectively. The results from the TaqMan SNP assay were confirmed by PCRRFLP analysis using the $B c l I$ and N363S restriction enzymes and digestion for $1 \mathrm{~h}$ at $37^{\circ} \mathrm{C}$.

\section{Statistical analysis}

Analyses were conducted using linear regression for continuous response variables and logistic regression for binary response variables (elevated 
blood pressure and hyperlipidemia). For the binary responses the results are presented as odds ratios (OR), i.e. the odds of the response being present are increased by the reported ratio for every one unit increase in the predictor.

A series of regression models were constructed focusing on ethnicity as a predictor. First, an unadjusted model was constructed. The second model was adjusted for age. The third was adjusted for age and genotype. Fourth, a full model containing every covariate was fashioned. Finally, a parsimonious model was built using a manual backward elimination technique while providing that ethnicity remained in the model. The AA group (group 2) was further examined with the same approach, while genotype served as the primary predictor. Statistical significance was defined as $\alpha<0.05$.

\section{RESULTS}

Blood samples of the two groups of individuals (26 Caucasian and $23 \mathrm{AA}$ ) were analyzed for N363S and $\mathrm{Bcl} / \mathrm{I}$ polymorphisms. All of the participants in our study were found to carry a homozygous genotype $(\mathrm{N} 363 \mathrm{~N})$. Genotype frequencies of the Bcl/I polymorphism in the GR gene for our two groups were: group $1(\mathrm{CC}=35 \%, \mathrm{CG}=46 \%$ and $\mathrm{GG}=19 \%)$ and group 2 (CC $=57 \%$ and $\mathrm{CG} 39 \%$ ). Demographic information for the participants and results are shown in Table 2.

White participants were on average 49 years old with BMIs of $30.7 \mathrm{~kg} / \mathrm{m}^{2}$, while AA participants were on average 46 years old with BMIs of $37.3 \mathrm{~kg} / \mathrm{m}^{2}$. BMI ( $p=0.012)$, HBA1c $(p=0.030)$, fasting glucose, $(p=0.071)$ and fasting insulin $(p=0.092)$ showed potential differences between ethnicities. A lower percentage of our white participants $(38 \%)$ had elevated blood pressure compared with AA (52\%).

Waist circumference ranged from $87 \mathrm{~cm}$ to 143 $\mathrm{cm}$ in black women, and from 65 to $139 \mathrm{~cm}$ in white women. Hip circumference ranged from $101 \mathrm{~cm}$ to $150 \mathrm{~cm}$ in black women, and from $57 \mathrm{~cm}$ to $145 \mathrm{~cm}$ in white women.

Age and $\mathrm{HbA} 1 \mathrm{c}$ differences were supported between AA and white participants, primarily occurring for the $\mathrm{CC}$ genotype, while only BMI showed a statistically significant difference for the CG geno- type. BMI, HbA1c, and fasting insulin also showed potential differences between our two groups and were followed up in adjusted models.

Regression analyses were used to examine the effect of the ethnicity on metabolic/CVD outcomes. Unadjusted, adjusted for age, $B c l I$, and fully and parsimonious models were included in our statistical analyses to observe any increasing statistical significance along our regression models. Logistic regression odds ratios were reported for binary variables (elevated BP and hyperlipidemia), and where we had problems with the collinearity of our variables we excluded them from the regression model.

We started the analysis of our metabolic/CVD outcomes with an unadjusted regression model. This initial model suggested a possible effect of genotype on the relationship between ethnicity and BMI (6.62, $\mathrm{p}=0.010)$, waist-to-hip ratio $(0.04, \mathrm{p}=0.081)$, $\log (\mathrm{HOMA}-\mathrm{IR})(0.37, \mathrm{p}=0.081)$, and HbA1c $(0.28$, $\mathrm{p}=0.059)$.

To examine further our primary question of the effect of genotype on the relationship between ethnicity and metabolic/CVD outcomes, we added subsequently age and $B c l$ I polymorphism to the initial unadjusted model.

The adjusted relationships between ethnicity and the outcomes remained similar when age was added to the initial model. We observed a stronger statistical difference in this model 1 for BMI $(7.89, \mathrm{p}=0.001)$, waist-to-hip ratio (0.053, $\mathrm{p}=0.035), \log$ (HOMA-IR) $(0.42, \mathrm{p}=0.05)$, and HbA1c $(0.34, \mathrm{p}=0.021)$.

For the relationships between ethnicity and the metabolic/CVD outcomes (Table 3), African American ethnicity was associated with a $7.89 \mathrm{~kg} / \mathrm{m}^{2}$ higher BMI in age adjusted models (95\% CI: [3.27, 12.51]), $\mathrm{p}=0.001$. AA also showed higher waist-to-hip ratios, 0.053 (95\% CI: [0.003, 0.10]), $\mathrm{p}=0.035, \log$ (HOMAIR), 0.42 (95\% CI: [-0.007, 0.84]) $\mathrm{p}=0.05$ and HbA1c 0.34 (95\% CI: [0.057, 0.64]) $\mathrm{p}=0.021$. The other response variables did not reach statistical power to conclude that ethnicity was a significant predictor.

The results obtained after the addition of the $B c l$ I polymorphism to the regression model have indicated that the $B c l$ I polymorphism is unlikely to be the driver of observed ethnicity differences in the 
Table 2. Mean values and standard deviation (SD) for clinical, biochemical, and psychological parameters for the Bc/I polymorphism (C and $\mathrm{G}$ alleles) in Caucasian and African American Mississippians

\begin{tabular}{|c|c|c|c|c|c|c|c|}
\hline \multirow[b]{3}{*}{ Characteristics } & \multicolumn{4}{|c|}{ Caucasian (white) } & \multicolumn{3}{|c|}{ African American (black) } \\
\hline & $\mathrm{CC}$ & CG & GG & Total & $\mathrm{CC}$ & CG & Total \\
\hline & $\mathrm{N}=9(35 \%)$ & $\mathrm{N}=12(46 \%)$ & $\mathrm{N}=5(19 \%)$ & $\mathrm{N}=26$ & $\mathrm{~N}=13(57 \%)$ & $\mathrm{N}=9(39 \%)$ & $\mathrm{N}=\mathbf{2 3}$ \\
\hline Age (y) & $\begin{array}{c}52.8 \\
(11.1)\end{array}$ & $\begin{array}{c}47.3 \\
(12.6)\end{array}$ & $\begin{array}{c}46.8 \\
(14.5)\end{array}$ & $\begin{array}{c}49.1 \\
(12.3)\end{array}$ & $\begin{array}{l}45.2 \\
(7.8)\end{array}$ & $\begin{array}{c}45 \\
(7.68)\end{array}$ & $\begin{array}{l}45.5 \\
(7.6)\end{array}$ \\
\hline BMI & $\begin{array}{l}33.8 \\
(9.6)\end{array}$ & $\begin{array}{l}28.8 \\
(9.4)\end{array}$ & $\begin{array}{l}29.8 \\
(9.7)\end{array}$ & $\begin{array}{l}30.7 \\
(9.4)\end{array}$ & $\begin{array}{l}39.55 \\
(8.69)\end{array}$ & $\begin{array}{l}35.03 \\
(4.93)\end{array}$ & $\begin{array}{l}37.3 \\
(7.6)\end{array}$ \\
\hline Waist-to-hip ratio & $\begin{array}{c}0.86 \\
(0.08)\end{array}$ & $\begin{array}{l}0.82 \\
(0.1)\end{array}$ & $\begin{array}{c}0.83 \\
(0.07)\end{array}$ & $\begin{array}{l}0.83 \\
(0.1)\end{array}$ & $\begin{array}{c}0.88 \\
(0.05)\end{array}$ & $\begin{array}{c}0.85 \\
(0.05)\end{array}$ & $\begin{array}{c}0.88 \\
(0.06)\end{array}$ \\
\hline Fasting insulin & $\begin{array}{c}10.5 \\
{[6.7-22.3]}\end{array}$ & $\begin{array}{c}8.7 \\
{[6.4-20.7]}\end{array}$ & $\begin{array}{c}10.2 \\
{[7.07-16.56]}\end{array}$ & $\begin{array}{c}9.8 \\
{[6.72-19.85]}\end{array}$ & $\begin{array}{c}18.36 \\
{[11.34-29.9]}\end{array}$ & $\begin{array}{c}15.81 \\
{[13.07-18.62]}\end{array}$ & $\begin{array}{c}17.08 \\
{[12.2-24.26]}\end{array}$ \\
\hline Fasting glucose & $\begin{array}{l}95.8 \\
(6.5)\end{array}$ & $\begin{array}{l}93.41 \\
(13.6)\end{array}$ & $\begin{array}{c}90.6 \\
(11.01)\end{array}$ & $\begin{array}{c}93.7 \\
(10.8)\end{array}$ & $\begin{array}{l}102.23 \\
(11.38)\end{array}$ & $\begin{array}{l}94.22 \\
(8.05)\end{array}$ & $\begin{array}{c}99.52 \\
(10.82)\end{array}$ \\
\hline HOMA-IR & $\begin{array}{c}2.4 \\
{[1.4-5.5]}\end{array}$ & $\begin{array}{c}2.1 \\
{[1.3-4.3]}\end{array}$ & $\begin{array}{c}2.1 \\
{[1.4-3.9]}\end{array}$ & $\begin{array}{c}2.2 \\
{[1.36-4.56]}\end{array}$ & $\begin{array}{c}4.1 \\
{[2.5-7.3]}\end{array}$ & $\begin{array}{c}3.8 \\
{[3-4.3]}\end{array}$ & $\begin{array}{c}3.95 \\
{[2.75-5.8]}\end{array}$ \\
\hline Fructoseamine & $\begin{array}{l}220.1 \\
(22.8)\end{array}$ & $\begin{array}{c}226.3 \\
(20.84)\end{array}$ & $\begin{array}{c}222.8 \\
(19.65)\end{array}$ & $\begin{array}{l}223.46 \\
(20.67)\end{array}$ & $\begin{array}{l}218.76 \\
(20.64)\end{array}$ & $\begin{array}{l}222.11 \\
(12.72)\end{array}$ & $\begin{array}{l}220.52 \\
(17.24)\end{array}$ \\
\hline $\mathrm{HbA1c}$ & $\begin{array}{c}5.8 \\
(0.3)\end{array}$ & $\begin{array}{l}5.64 \\
(0.7)\end{array}$ & $\begin{array}{l}5.64 \\
(0.5)\end{array}$ & $\begin{array}{c}5.68 \\
(0.53)\end{array}$ & $\begin{array}{c}6.15 \\
(0.47)\end{array}$ & $\begin{array}{c}5.67 \\
(0.44)\end{array}$ & $\begin{array}{c}5.97 \\
(0.51)\end{array}$ \\
\hline Salivary cortisol & $\begin{array}{l}150 \\
(60)\end{array}$ & $\begin{array}{l}180 \\
(10)\end{array}$ & $\begin{array}{c}190 \\
(160)\end{array}$ & $\begin{array}{l}170 \\
(10)\end{array}$ & $\begin{array}{l}170 \\
(90)\end{array}$ & $\begin{array}{l}130 \\
(70)\end{array}$ & $\begin{array}{l}160 \\
(80)\end{array}$ \\
\hline PSS & $\begin{array}{l}14.2 \\
(5.6)\end{array}$ & $\begin{array}{l}12.8 \\
(8.6)\end{array}$ & $\begin{array}{c}19.4 \\
(12.42)\end{array}$ & $\begin{array}{l}14.7 \\
(8.5)\end{array}$ & $\begin{array}{c}16 \\
(6.16)\end{array}$ & $\begin{array}{l}15.28 \\
(4.11)\end{array}$ & $\begin{array}{c}15.2 \\
(5.76)\end{array}$ \\
\hline Elevated BP & $\begin{array}{c}7 \\
(78 \%)\end{array}$ & $\begin{array}{c}3 \\
(25 \%)\end{array}$ & 0 & $\begin{array}{c}10 \\
(38 \%)\end{array}$ & $\begin{array}{c}7 \\
(54 \%)\end{array}$ & $\begin{array}{c}4 \\
(44 \%)\end{array}$ & $\begin{array}{c}12 \\
(52 \%)\end{array}$ \\
\hline Hyperlipidemia & $\begin{array}{c}4 \\
(44 \%)\end{array}$ & $\begin{array}{c}2 \\
(17 \%) \\
\end{array}$ & $\begin{array}{c}1 \\
(20 \%)\end{array}$ & $\begin{array}{c}7 \\
(27 \%) \\
\end{array}$ & $\begin{array}{c}2 \\
(15 \%) \\
\end{array}$ & $\begin{array}{c}1 \\
(11 \%) \\
\end{array}$ & $\begin{array}{c}4 \\
(17 \%) \\
\end{array}$ \\
\hline
\end{tabular}

\begin{tabular}{lccc}
\hline \multicolumn{4}{c}{ Comparison Caucasian vs African American } \\
\hline \multirow{3}{*}{ Characteristics } & CC & CG & Total \\
\hline Age & 0.019 & 0.413 & 0.057 \\
BMI & 0.229 & 0.055 & 0.012 \\
Waist to hip ratio & 0.788 & 0.594 & 0.277 \\
Fasting insulin & 0.270 & 0.286 & 0.092 \\
Fasting glucose & 0.227 & 0.569 & 0.071 \\
HOMA-IR & 0.216 & 0.255 & 0.058 \\
Fructoseamine & 0.736 & 0.749 & 0.595 \\
HbA1c & 0.051 & 0.567 & 0.030 \\
Salivary cortisol & 0.525 & 0.200 & 0.724 \\
PSS & 0.521 & 0.463 & 0.554 \\
Elevated BP & 0.38 & 0.397 & 0.396 \\
Hyperlipidemia & 0.178 & $>0.999$ & 0.506 \\
\hline
\end{tabular}

* p value for unadjusted differences; Nonparametric Wilcoxon Rank Sum tests for continuous vars, Fisher's exact test for categorical * values in table are $\mathrm{N}(\%)$ for categorical vars, median [IQR] for skewed continuous vars (HOMA-IR, Insulin), mean (SD) otherwise * only 1 African American GG genotype was observed; BP: blood pressure; PSS: perceived stress scale. 
Table 3. Ethnicity Associations - Mediation Effect Regression Models

\begin{tabular}{|c|c|c|c|c|c|}
\hline \multirow[b]{2}{*}{ Outcome } & \multicolumn{5}{|c|}{ Ethnicity Effect } \\
\hline & Unadjusted & $\begin{array}{c}\text { Model 1: } \\
\text { Adjusted for age }\end{array}$ & $\begin{array}{c}\text { Model 2: } \\
\text { Model 1 + Bcl1 }\end{array}$ & $\begin{array}{c}\text { Model 3: } \\
\text { Full Model }\end{array}$ & $\begin{array}{c}\text { Model 4: } \\
\text { Parsimonious }\end{array}$ \\
\hline BMI & $\begin{array}{c}6.62 \mathrm{p}=0.010 \\
(1.65,11.58)\end{array}$ & $\begin{array}{c}7.89 p=0.001 \\
(3.27,12.51)\end{array}$ & $\begin{array}{c}6.85 \mathrm{p}=0.006 \\
(2.09,11.62)\end{array}$ & $\begin{array}{c}1.29 p=0.488 \\
(-2.48,5.06)\end{array}$ & $\begin{array}{c}3.13 p=0.039 \\
(0.16,6.10)\end{array}$ \\
\hline Waist-to-hip ratio & $\begin{array}{l}0.04 p=0.081 \\
(-0.005,0.09)\end{array}$ & $\begin{array}{c}0.053 \mathrm{p}=0.035 \\
(0.003,0.10)\end{array}$ & $\begin{array}{c}0.053 \mathrm{p}=0.044 \\
(0.001,0.10)\end{array}$ & $\begin{array}{l}0.029 p=0.282 \\
(-0.025,0.085)\end{array}$ & $\begin{array}{l}0.023 p=0.276 \\
(-0.019,0.066)\end{array}$ \\
\hline Log (HOMA-IR) & $\begin{array}{l}0.37 p=0.081 \\
(-0.048,0.79)\end{array}$ & $\begin{array}{l}0.42 p=0.050 \\
(-0.007,0.84)\end{array}$ & $\begin{array}{c}0.37 p=0.100 \\
(-0.08,0.82)\end{array}$ & $\begin{array}{c}-0.2 p=0.322 \\
(-0.60,0.20)\end{array}$ & $\begin{array}{l}-0.07 p=0.654 \\
(-0.383,0.243)\end{array}$ \\
\hline Fructosamine & $\begin{array}{c}-2.93 p=0.593 \\
(-13.96,8.08)\end{array}$ & $\begin{array}{c}-3.74 p=0.501 \\
(-14.98,7.49)\end{array}$ & $\begin{array}{c}-2.87 p=0.637 \\
(-14.80,9.06)\end{array}$ & $\begin{array}{c}1.63 p=0.781 \\
(-10.54,13.80)\end{array}$ & $\begin{array}{l}2.67 p=0.552 \\
(-6.31,11.66)\end{array}$ \\
\hline $\mathrm{HbA1c}$ & $\begin{array}{l}0.28 p=0.059 \\
(-0.011,0.59)\end{array}$ & $\begin{array}{c}0.34 p=0.021 \\
(0.057,0.64)\end{array}$ & $\begin{array}{c}0.31 p=0.042 \\
(0.009,0.61)\end{array}$ & $\begin{array}{c}0.097 \mathrm{p}=0.513 \\
(-0.20,0.39)\end{array}$ & $\begin{array}{l}0.012 p=0.918 \\
(-0.224,0.249)\end{array}$ \\
\hline Salivary cortisol & $\begin{array}{c}-0.02 p=0.535 \\
(-0.076,0.04)\end{array}$ & $\begin{array}{c}-0.024 p=0.422 \\
(-0.085,0.036)\end{array}$ & $\begin{array}{c}-0.022 p=0.496 \\
(-0.087,0.043)\end{array}$ & $\begin{array}{c}-0.024 p=0.535 \\
(-0.10,0.054)\end{array}$ & $\begin{array}{c}-0.014 p=0.616 \\
(-0.07,0.042)\end{array}$ \\
\hline PSS & $\begin{array}{c}0.49 p=0.827 \\
(-4.04,5.02)\end{array}$ & $\begin{array}{c}0.76 p=0.747 \\
(-3.86,5.39)\end{array}$ & $\begin{array}{c}1.03 p=0.671 \\
(-3.88,5.94)\end{array}$ & $\begin{array}{c}2.56 p=0.414 \\
(-3.83,8.96)\end{array}$ & $\begin{array}{c}0.73 p=0.759 \\
(-4.05,5.52)\end{array}$ \\
\hline Elevated BP* & $\begin{array}{c}1.74 p=0.331 \\
(0.55,5.44)\end{array}$ & $\begin{array}{c}2.38 p=0.171 \\
(0.67,8.40)\end{array}$ & $\begin{array}{c}1.73 p=0.422 \\
(0.44,6.74)\end{array}$ & $\begin{array}{l}3.42 p=0.262 \\
(0.38,30.43)\end{array}$ & $\begin{array}{c}1.57 p=0.498 \\
(0.42,5.85)\end{array}$ \\
\hline Hyperlipidemia* & $\begin{array}{c}0.57 \mathrm{p}=0.426 \\
(0.14,2.27)\end{array}$ & $\begin{array}{c}1.67 p=0.579 \\
(0.27,10.19)\end{array}$ & $\begin{array}{c}1.72 p=0.573 \\
(0.26,11.23)\end{array}$ & $\begin{array}{c}1.31 p=0.863 \\
(0.06,28.8)\end{array}$ & $\begin{array}{l}1.72 p=0.570 \\
(0.264,11.24)\end{array}$ \\
\hline
\end{tabular}

*Note: AA - Caucasian

*Elevated BP \& Hyperlipidemia are binary variables, logistic regression Odds Ratios and 95\% CI are reported

**Hyperlipidemia full model excluded Waist-to-Hip Ratio due to collinearity induced nonconvergence issues.

metabolic/ CVD outcomes. The initially supported statistically relationships were weakened for BMI $(6.85, \mathrm{p}=0.006)$, waist-to-hip ratio $(0.053, \mathrm{p}=0.044)$, and HbA1c (0.31, $\mathrm{p}=0.042)$ and just marginally important for $\log$ (HOMA-IR) $(0.37, p=0.100)$.

We additionally constructed fully adjusted and parsimonious models to examine any additional relationships between the selected variables and ethnicity. Only the BMI showed any significant difference across ethnicities, with African Americans showing an estimated $3.13 \mathrm{~kg} / \mathrm{m}^{2}$ higher BMI after adjusting for $\log$ (HOMA-IR), fructosamine, and HbA1c. Waistto-hip ratio, log (HOMA-IR), and HbA1c outcomes, which statistically supported differences in age and $B c l$ adjusted models between CC and CG ethnic genotypes, have ceased to support these substantial changes after adjustment made in full and parsimonious models. The adjustments in the parsimonious regression model for the aforementioned three out- comes were: BMI and hyperlipidemia for waist-to-hip ratio; fructosamine and $\mathrm{HbA} 1 \mathrm{c}$ for log (HOMA-IR); BMI, $\log$ (HOMA-IR), and fructosamine for HbA1c. These variables have contributed significantly to the variance of these three outcomes. Full model and complete parsimonious model estimates are available from the authors on request.

As an additional part to our research project we investigated the effects of the $\mathrm{C}$ and $\mathrm{G}$ allele on metabolic/CVD outcomes within AA group. In Table 4 , we have presented the results of our analyses for group 2 AA.

Our 23 AA females were analyzed for the prevalence of the $B c l$ I polymorphism. Allele and genotype frequencies of the $B c l$ I polymorphism in the GR gene identified in our AA group are displayed in Table 2. We found 13 homozygous CC (57\%), 9 heterozygous CG (39\%), and one homozygous GG. 
Table 4. $B c l$ I Effect (CG versus CC) within African Americans

\begin{tabular}{lcccccc}
\hline Outcome & \multicolumn{2}{c}{ Unadjusted } & \multicolumn{2}{c}{ Model 1: Adjusted for Age } & \multicolumn{2}{c}{ Model 2: Parsimonious } \\
\hline BMI & $-4.52 p=0.176$ & $(-11.23,2.19)$ & $-4.44 p=0.123$ & $(-10.18,1.31)$ & $0.011 p=0.996$ & $(-4.25,4.28)$ \\
Waist to hip ratio & $-0.027 \mathrm{p}=0.264$ & $(-0.077, .022)$ & $-0.027 \mathrm{p}=0.274$ & $(-0.078,0.023)$ & $-0.0025 \mathrm{p}=0.901$ & $(-0.044,0.039)$ \\
Log (HOMA-IR) & $-0.21 \mathrm{p}=0.417$ & $(-0.72,0.31)$ & $-0.202 \mathrm{p}=0.419$ & $(-0.71,0.31)$ & $0.23 \mathrm{p}=0.268$ & $(-0.191,0.646)$ \\
Fructosamine & $3.34 \mathrm{p}=0.671$ & $(-12.85,19.53)$ & $3.32 \mathrm{p}=0.681$ & $(-13.31,19.94)$ & $13.99 \mathrm{p}=0.001$ & $(6.83,21.16)$ \\
HbA1c & $-0.48 \mathrm{p}=0.029$ & $(-0.898,-0.054)$ & $-0.47 \mathrm{p}=0.028$ & $(-0.891,-0.056)$ & $-0.31 \mathrm{p}=0.037$ & $(-0.604,-0.021)$ \\
Salivary cortisol & $-0.049 \mathrm{p}=0.214$ & $(-0.128,0.031)$ & $-0.048 \mathrm{p}=0.240$ & $(-0.130,0.035)$ & $-0.061 \mathrm{p}=0.062(-0.125,0.0035)$ \\
PSS & $-0.71 \mathrm{p}=0.789$ & $(-6.26,4.83)$ & $-1.21 \mathrm{p}=0.632$ & $(-6.48,4.06)$ & $-3.56 \mathrm{p}=0.217$ & $(-9.44,2.32)$ \\
Elevated BP*+ & $0.686 \mathrm{p}=0.665$ & $(0.124,3.78)$ & $0.686 \mathrm{p}=0.667$ & $(0.123,3.82)$ & $0.686 \mathrm{p}=0.665$ & $(0.124,3.78)$ \\
Hyperlipidemia** & $0.688 \mathrm{p}=0.775$ & $(0.053,8.96)$ & $0.695 \mathrm{p}=0.795$ & $(0.045,10.83)$ & &
\end{tabular}

+ The parsimonious model for hypertension was found to be the same as the unadjusted model

† The parsimonious model for hyperlipidemia failed to converge due to possible collinearity issues.

In the unadjusted and age adjusted models, the only statistically significant difference between CC and CG genotypes was observed for HbA1c: $(-0.48$, $\mathrm{p}=0.029)$ and $(-0.47, \mathrm{p}=0.028)$, respectively. None of the other reported relationships between the aforementioned genotypes and clinical parameters were confirmed in our study. However, after we constructed parsimonious models to correct for the effects of all physiological variables, other differences between our homozygous and heterozygous AA subjects were identified.

Although in the initial models (unadjusted and adjusted for age) fructosamine did not show any statistical importance between CC and CG genotypes, after correcting for BMI log (HOMA-IR), HbA1c and cortisol - the variables with significant contribution to variance in fructosamine - the relationship grew stronger to a significant statistical difference (13.99, $\mathrm{p}=0.001)$. The HbA1c difference between CC and CG genotypes remained statistically important also in our parsimonious model after correcting for the effects of BMI, log (HOMA-IR), and fructosamine (variables with significant contribution to variance in $\mathrm{HbA1c})(-0.31, \mathrm{p}=0.037)$.

The latest statistically significant relationship between $\mathrm{CC}$ and $\mathrm{CG}$ genotypes in regard to clinical parameters analyzed in our parsimonious model was observed for cortisol. After adjusting for fructosamine and elevated $\mathrm{BP}$ - variables with significant contribution to variance in cortisol - our statistical results have confirmed marginally this relationships for cor- tisol $(-0.061, p=0.062)$. None of the other variables analyzed (BMI, waist-to-hip ratio, log (HOMA-IR), PSS, elevated BP, and hyperlipidemia) in unadjusted, adjusted for age, and in parsimonious models have shown any significant relationships for the $B c l$ I polymorphism within the AA group.

\section{DISCUSSION}

Obesity and hypertension are increasing in many societies worldwide. Although most of this epidemic is simply attributable to miscalculating caloric intake and loss by behavioral and environmental issues, there are also genetic contributors. As is true for many complex traits, most likely a combination and corroboration of many altered genes increases the susceptibility for becoming overweight rather than a single gene alteration. However, to better understand mechanisms of disease, studying monogenic disorders or those in which one specific gene may be altered still represents a fruitful avenue for discovery and advancement of knowledge. ${ }^{38}$ In this study, we attempted to assess the impact of polymorphisms N363S and BclI of the GR gene on various metabolic, anthropometric, and psychological parameters in relationship to obesity. AA seem to be more sensitive to glucocorticoids than Caucasian Americans, with greater peak insulin and postprandial insulin areas under the curve. ${ }^{19} \mathrm{AA}$ also appear to have higher sweet taste perception scores when compared with Caucasians..$^{39}$ In previous studies not including AA individuals from Mississippi, a state with a high poverty level in addition to having 
the highest percentage $(68 \%)$ of overweight and obese individuals in the United States, these two SNPs of the GR have been found to be associated with a milieu of glucocorticoid hypersensitivity, leading to more body fat, less lean mass, higher insulin secretion, and higher cholesterol levels (reviewed in 33,34). Any impact of N363S was ruled out in our study group, as all participants were homozygous for $\mathrm{N} 363 \mathrm{~N}$ (wild-type). However, the $\mathrm{Bcl}$ I polymorphism with its $\mathrm{C}$ and $\mathrm{G}$ alleles was found in various frequencies in our two study groups.

Our data for $\mathrm{C}$ and $\mathrm{G}$ allele frequencies of the $B c l$ I polymorphism in white females are similar for the CG genotype and slightly different for the CC and GG genotypes compared with data published previously. ${ }^{31}$ In the AA group (group 2, $n=23$ ), the $\mathrm{C}$ and $\mathrm{G}$ allele proportions were different both for homozygotes (CC and GG) and heterozygotes (CG). A previously published report found allele frequencies of 5\% CC (compared to ours: $57 \%$ ), $31 \%$ CG (compared to ours: $39 \%$ ), and $64 \%$ for GG. ${ }^{31}$ Whether this implies linkage disequilibrium which may alter the transcriptional activity of target genes that are important in glucose, insulin, and cholesterol metabolism, is unknown and we cannot make additional comments about these results due to the fact that we analyzed only female subjects and have incorporated only a small number of patients in our study.

Based on the paucity of data in the AA population, it is difficult to define precisely the role of the $B c l$ I polymorphism in our female population and associations with various metabolic/CVD outcomes. In Caucasian women, sequence variants in both the $\mathrm{N} 363 \mathrm{~S}$ and the BclI polymorphism may result in higher cholesterol levels and a tendency for higher blood pressure. ${ }^{40}$

In the main part of our study, we intended to search for ethnic differences between homozygous and heterozygous genotypes related to the $\mathrm{C}$ and $\mathrm{G}$ allele of the BclI polymorphism.

We compared Caucasian and AA females (homozygous and heterozygous genotypes) using a set of metabolic/CVD and stress outcomes (physiological and psychological stresses).

Multiple studies published before have stressed the role of $B c l I$ and $\mathrm{N} 363 \mathrm{~S}$ polymorphisms on various clinical parameters. In our subjects we studied the interethnic variability of nine clinical parameters: BMI, waist-to-hip ratio, log (HOMA-IR), fructosamine, HbA1c, salivary cortisol, PSS, elevated blood pressure/hypertension, and hyperlipidemia.

Previous studies have found statistically different outcomes for most of these parameters analyzed for both BclI and N363S SNPs within the same ethnic group but did not investigate further if the ethnicity factor plays a role here.

An interesting finding in our study working with different regression models was that adding the $B c l$ I polymorphism to model 1 (see Table 3 ) made the relationship grow weaker statistically for all of the nine outcomes investigated, suggesting a limited or no effect on these variables.

Some studies have shown an increased subcutaneous fat deposition in women who carry a BclI or N363S polymorphism. In our study, the only statistically significant interethnic difference was observed for BMI. Waist-to-hip ratio, although showing a statistical difference between these two ethnic groups in the adjusted model for age and $B c l$, failed to show any race differences after correcting for the interference of other parameters in parsimonious models. For parameters such as BMI, waist-to-hip ratio, and waist circumference, controversy exists regarding superiority in cardiometabolic risk prediction, and international experts recommend the use of population-specific and country-specific definitions for waist circumference and BMI. The new Asian BMI criteria include a lower cut-off of $23.0 \mathrm{~kg} / \mathrm{m}^{2}$ for defining overweight Asians and of $25.0 \mathrm{~kg} / \mathrm{m}^{2}$ for identifying obesity in Asians. Srivastava et $\mathrm{l}^{35}$ concluded that the GG genotype of the $B c l$ I polymorphism in the GR gene modulates blood pressure and blood glucose in Northern Indians with a waist-to-hip ratio of 0.95 . On the other hand, neither BMI nor waist circumference nor waist-to-hip ratio identified newly diagnosed type 2 diabetics or hypertensives with a high sensitivity or specificity in 2,477 men and 3,107 women, aged 20-79 years, from the Pudong new area of Shanghai in China. ${ }^{41}$ In the SABPA study of Sub-Saharan Africans, investigators suggested that the optimal cut-off point in waist circumference for males be set at $90 \mathrm{~cm}$, as opposed to 
the present $94 \mathrm{~cm}$, and for females be set at $98 \mathrm{~cm}$, compared to the current cut-off of $80 \mathrm{~cm} .{ }^{42}$ NHANES data (1999-2006) of non-minority American adults aged 52-85 years showed much higher rates of type 2 diabetes and waist circumference at each level of BMI compared to an equivalent group in England (2004 English Longitudinal Study of Aging), suggesting that waist circumference in this group is superior in predicting cardiometabolic risk. ${ }^{43}$ A prospective cohort study comprising 9,753 German men and 15,491 German women, aged 35-65 years, similarly concluded that waist circumference represents a better marker to predict diabetes risk than the BMI. ${ }^{44}$

The addition of the $B c l$ I polymorphism to our regression models seemed to detect a possible association between this polymorphism and log (HOMA-IR) and $\mathrm{HbA} 1 \mathrm{c}$ (model 2). These relationships between the metabolic outcomes of Caucasian and AA females from Mississippi lost their statistical significance in full and in parsimonious regression models for log HOMA-IR and for HbA1c. Using HbA1c for the diagnosis of diabetes in adults is problematic and even more so in children and adolescents. ${ }^{45-47}$ A HbA1c cut-off of $6.5 \%$ would miss approx. $50 \%$ of diabetic children and adolescents aged 12-18 years (area under curve value of 0.88 in ROC analysis, compared to 0.93 in adults) ${ }^{48}$ In Chinese subjects, the sensitivity of $\mathrm{HbA} 1 \mathrm{c}>6.5 \%$ for the diagnosis of diabetes was $48 \%$, with a specificity of $98 \% .^{49} \mathrm{~A}$ recent meta-analysis of genome-wide association studies including 46,000 Europeans without diabetes mellitus revealed that genetic factors affecting expression, turnover, and abnormal glycation of hemoglobin could be associated with increased levels of $\mathrm{HbA} 1 \mathrm{c} .{ }^{20}$ Further complicating the assessment of $\mathrm{HbA} 1 \mathrm{c}$ is the fact that one also has to consider that type 1 and type 2 diabetics may involve a dysfunction of the hypothalamic-pituitary-adrenal axis with flattened circadian cortisol rhythm. ${ }^{50,51}$ In patients with hypercortisolism caused by Cushing's disease, diabetes mellitus type 2 and hypertension are risk factors for worse outcome..$^{52}$

When we searched for interracial differences in our groups in relation to CVD outcomes, we found no difference in elevated BP and hyperlipidemia in the parsimonious model. Although these two CVD outcomes may play a role in women who carry these two polymorphisms - as reported in some studies - they did not seem to differ between these two races. In regression model 2 after adding the $B c l$ I polymorphism, no statistical difference was observed for elevated BP and hyperlipidemia.

The last outcomes analyzed in our study were related to stress. Stress can affect many body functions and depends on numerous factors including stress perception, stress coping and behavior modification and adaptation, individual hormonal responses, and others. ${ }^{3,53,54}$ Of interest, the norm table for the PSS 10 item inventory reports a mean of 12.8 for white, of 14.7 for black, of 14.0 for Hispanic, and of 14.1 for other minorities. In our groups (see Table 2), PSS scores and cortisol levels did not differ (model 4). The presence of the $B c l$ I polymorphism in both groups seemed to attenuate interracial differences in coping with stress. With PSS mean scores of 14.7 for whites and of 15.2 for blacks, therefore only slightly above the reported norm mean, one cannot conclude that Mississippians experience/perceive more stress, although an environment with high poverty and low education levels certainly can cause stress. ${ }^{6}$ The question arises whether coping mechanisms are utilized in the sense of stress desensitization. Certainly, the right amount of stress sometimes referred to as eustress can have many positive effects, as opposed to chronic "kakostress" (distress). Simply put, a high BMI around other people with high BMI $(68 \%$ of the population in Mississippi) may not be perceived as abnormal but rather as the norm, therefore not causing any kind of stress. This type of norm change (oversizing) is also reflected by industrial efforts, for instance by moving up the waist circumference defined for a certain clothing size (i.e. jeans size 32 in 1993 is now size 30, allowing people to keep gaining weight and psychologically think "I am still in good/normal shape"). To initiate behavior change, i.e. regarding lifestyle modifications including more physical activity and healthier food choices, a certain amount of eustress is necessary. Practically put, the time has now come to "downsize" and confront people with their body sizes/shapes by re-setting parameters such as definition of a normal BMI, normal waist and hip circumference including size for jeans, suits, dresses, and other clothing.

Although it is premature to draw any conclusion about interracial differences in homozygous and 
heterozygous individuals with the $B c l$ I polymorphism, different ethnic background, and metabolic/CVD and stress outcomes, we did not observe a significant difference, at least in our Mississippian study population. The only positive interethnic outcome studied was BMI (higher in blacks compared to whites).

As an additional project to our study we investigated the impact of the $B c l$ I polymorphism within the AA ethnic group. Such analyses have not been reported extensively in the literature and the results for the AA group based on the influence of the $B c l$ I polymorphism on these nine outcomes are not known. We analyzed the differences between the hetero(CG) and homozygous (CC) AA females based on these nine different study parameters. We had only one case carrying the GG genotype and we dropped this case from our calculations.

In our study we found significant differences between our hetero- and homozygous participants for fructosamine, $\mathrm{HbA1c}$, and salivary cortisol levels (see Table 4).

We cannot report any difference between AA hetero- and homozygotes for $\mathrm{C}$ and $\mathrm{G}$ alleles for: BMI, waist-to-hip ratio, log (HOMA-IR), PSS, elevated blood pressure (parsimonious regression model, Table 4).

Although in Caucasian women included in this type of analysis BMI, hyperinsulinemia, elevated $\mathrm{BP}$, and hyperlipidemia have been considered to be altered by the presence of the $B c l I$ polymorphism, in our AA group we could not find these associations.

We are aware of the difficulties of extrapolating these data to the general AA, African, and Caucasian female populations due to the small number of subjects incorporated in our investigation. We hope larger studies, particularly on African populations, will be performed in the future to better define metabolic and psychological characteristics in relation to the N363S and BclI GR gene polymorphisms. Perhaps this information may then facilitate the identification of a new biomarker, analogous to SNPs in the CRP (C-reactive protein) gene..$^{55}$

No financial support other than departmental resources were used in the preparation of this manuscript. All authors meet full criteria for authorship and approve this manuscript in its final form. All authors attest that they have no real or apparent conflicts of interest, financial or intellectual, related to the content of this article.

\section{REFERENCES}

1. Centers for Disease Control and Prevention: overweight and obesity web site www.cdc.gov/obesity/index.html. accessed January 2012.

2. Yanovski SZ, Yanovski JA, 2011 Obesity prevalence in the United States - up, down, or sideways? N Engl J Med 364: 987-989.

3. Chrousos GP, 2009 Stress and disorders of the stress system. Nat Rev Endocrinol 5: 374-381.

4. Pervanidou P, Chrousos GP, 2012 Metabolic consequences of stress during childhood and adolescence. Metabolism 6: 611-619.

5. Scott KM, Bruffaerts R, Simon GE, et al, 2008 Obesity and mental disorders in the general population: results from the world mental health surveys. Int J Obes (Lond) 32: 192-200.

6. Stuckler D, Meissner C, Fishback P, et al, 2012 Banking crises and mortality during the Great Depression: evidence from US urban populations, 1929-1937. J Epidemiol Community Health 66: 410-419.

7. Siervo M, Wells JC, Cizza G, 2009 The contribution of psychosocial stress to the obesity epidemic: an evolutionary approach. Horm Metab Res 41: 261-270.

8. Kyrou I, Tsigos C, 2008 Chronic stress, visceral obesity and gonadal dysfunction. Hormones (Athens) 7: 287293.

9. Krassas GE, Kelestimur F, Micic D, et al, Balkan Group for the Study of Obesity, 2003 Self-reported prevalence of obesity among 20,329 adults from large territories of Greece, Serbia, and Turkey. Hormones (Athens) 2: 49-54.

10. Hassapidou M, Papadopoulou SK, Frossinis A, et al, 2009 Sociodemographic, ethnic and dietary factors associated with childhood obesity in Thessaloniki, Northern Greece. Hormones (Athens) 8: 53-59.

11. Newbold RR, 2010 Impact of environmental endocrine disrupting chemicals on the development of obesity. Hormones (Athens) 9: 206-217.

12. Koukoulis GN, Sakka C, Katsaros F, et al, 2010 High rates of obesity prevalence in adults living in central Greece: data from the ARGOS study. Hormones (Athens) 9: 253-262.

13. Clement K, 2006 Genetics of human obesity. CR Biologies 329 .

14. Wang HJ, Wermter AK, Nguyen TT, et al, 2007 No association of sequence variants in the neuropeptide Y2 receptor (NPY2R) gene with early onset obesity in Germans. Horm Metab Res 39: 840-844.

15. Almén MS, Jacobsson JA, Moschonis G, et al, 2012 
Genome wide analysis reveals association of a FTO gene variant with epigenetic changes. Genomics 99: 132-137.

16. Papazoglou D, Panagopoulos I, Papanas N, et al, 2008 The fatty acid amide hydrolase (FAAH) Pro129Thr polymorphism is not associated with severe obesity in Greek subjects. Horm Metab Res 40: 907-910.

17. Chung WK, 2012 An overview of monogenic and syndromic obesities in humans. Pediatr Blood Cancer 58: 122-128. doi: 10.1002/pbc. 23372.

18. Dav FR, Loos RJ, 2011 Developments in obesity genetics in the era of genome-wide association studies. $\mathrm{J}$ Nutrigenet Nutrigenomics 4: 222-238.

19. Frazier B, Hsiao CW, Deuster P, et al, 2010 African Americans and Caucasian Americans: differences in glucocorticoid-induced insulin resistance. Horm Metab Res 42: 887-891.

20. Soranzo N, Sanna S, Wheeler E, et al, 2010 Common variants at ten genomic loci influence hemoglobin A1C levels via glycemic and non-glycemic pathways. Diabetes 59: 3229-39.

21. Corvol H, Nathan N, Charlier C, et al, 2007 Glucocorticoid receptor gene polymorphisms associated with progression of lung disease in young patients with cystic fibrosis. Respiratory Research 8: 88.

22. Decorti G, De Iudicibus S, Stocco G, 2006 Glucocorticoid receptor polymorphisms in inflammatory bowel disease. Gut 55: 1053-1054.

23. van Oosten MJM, Dolhain RJEM, Koper JW, et al, 2010 Polymorphisms in the glucocorticoid receptor gene that modulate glucocorticoid sensitivity are associated with rheumatoid arthritis. Arthritis Res Ther 12: R159.

24. Bouamar R, Koper JW, van Rossum EFC, et al, 2009 Polymorphisms of the glucocorticoid receptor and avascular necrosis of the femoral heads after treatment with corticosteroids. NDT Plus 2: 384-386.

25. Szappanos A, Patoc A, Toke J, et al, 2009 BclI polymorphism of the glucocorticoid receptor gene is associated with decreased bone mineral density in patients with endogenous hypercortisolism. Clin Endocrinol 71: 636-643.

26. van Rossum EFC, Binderb EB, Majerb M, et al, 2006 Polymorphisms of the Glucocorticoid Receptor Gene and Major Depression. Biol Psychiatry 59: 681-688.

27. Stamatelopoulos K, Saltiki K, Mantzou E, et al, 2010 Subjects homozygous for the BCL1 polymorphism of glucocorticoid receptor gene may have an increased risk for impaired endothelial function. Endocrine Abstracts 22: P127.

28. Koch CA, 2012 Stress: aspects of endocrine hypertension. Dtsch Arztebl Int 109: 312.

29. Charmandari E, Kino T, Ichijo T, et al, 2008 Generalized glucocorticoid resistance: clinical aspects, molecular mechanisms, and implications of a rare genetic disorder. J Clin Endocrinol Metab 93: 1563-1572.

30. Charmandari E, Kino T, 2010 Chrousos syndrome: a seminal report, a phylogenetic enigma and the clinical implications of glucocorticoid signalling changes. Eur J Clin Invest 40: 932-942.

31. Fleury I, Beaulieu P, Primeau M, et al, 2003 Characterization of the $B c l$ I polymorphism in the glucocorticoid receptor gene. Clin Chem 49: 1528-1531.

32. Bray PJ, Cotton RG, 2003 Variations of the human glucocorticoid receptor gene (NR3C1): pathological and in vitro mutations and polymorphisms. Hum Mutat 21: 557-68.

33. Van Rossum EFC, Lamberts SW, 2004 Polymorphisms in the Glucocorticoid Receptor Gene and Their Associations with Metabolic Parameters and Body Composition. Recent Prog Horm Res 59: 333-357.

34. Manenschijn L, van den Akker EL, Lamberts SW, et al, 2009 Clinical features associated with glucocorticoid receptor polymorphisms. An overview. Ann N Y Acad Sci 1179: 179-198.

35. Srivastava N, Prakash J, Lakhan R, et al, 2011 Influence of Bcl-1 gene polymorphism of glucocorticoid receptor gene (NR3CL, rs41423247) on blood pressure, glucose in Northern Indians. Ind J Clin Biochem 26: 125-130.

36. Charmandari E, Ichijo T, Jubiz W, et al, 2008 A novel point mutation in the aminoacid terminal domain of the human glucocorticoid receptor gene (hGR) enhancing hGR-mediated gene expression. J Clin Endocrinol Metab 93: 4963-4968.

37. Andreou E, Alexopoulos EC, Lionis C, et al, 2011 Perceived stress scale: reliability and validity study in Greece. Int J Environ Res Public Health 8: 3287-98.

38. Koch CA, Pacak K, Chrousos GP, 2002 The molecular pathogenesis of hereditary and sporadic adrenocortical and adrenomedullary tumors. J Clin Endocrinol Metab 87: 5367-84.

39. DuFlo AR, Muniyappa R, Hall G, et al, 2011 Differences in sweet taste perception in African-Americans and Caucasians. Endocr Rev 32: OR38-6.

40. Di Blasio AM, Van Rossum EF, Maestrini S, et al, 2003 The relation between two polymorphisms in the glucocorticoid receptor gene and body mass index, blood pressure and cholesterol in obese patients. Clin Endocrinol (Oxf) 59: 68-74.

41. Gu JJ, Rafalson L, Zhao GM, et al, 2011 Anthropometric measurements for prediction of metabolic risk among Chinese adults in Pudong new area of Shanghai. Exp Clin Endocrinol Diabetes 119: 387-394.

42. Prinsloo J, Malan 1, de Ridder JH, et al, 2011 Determining the waist circumference cut off which best predicts the metabolic syndrome components in urban Africans: the SABPA study. Exp Clin Endocrinol Diabetes 119: 599-603.

43. Banks J, Kumari M, Smith JP, et al, 2012 What explains the American disadvantage in health compared with the English? The case of diabetes. J Epidemiol Community Health 66: 259-264.

44. Feller S, Boeing H, Pischon T, 2010 Body mass index, 
waist circumference, and the risk for type 2 diabetes mellitus: implications for routine clinical practice. Dtsch Arztebl Int 107: 470-476.

45. Nawroth PP, Rudofsky G, Humpert P, 2010 Have we understood diabetes? New tasks for diagnosis and therapy. Exp Clin Endocrinol Diab 118: 1-3.

46. Tay TL, Foo JP, Tan E, et al, 2011 HbA1c may not be a sensitive determinant of diabetic status in the elderly. Diabetes Res Clin Pract 92: e31-3.

47. Abdul-Ghani MA, Abdul-Ghani T, Müller G, et al, 2011 Role of glycated hemoglobin in the prediction of future risk of T2DM. J Clin Endocrinol Metab 96: 2596-600.

48. Lee JM, Wu EL, Tarini B, et al, 2011 Diagnosis of diabetes using hemoglobin A1C: should recommendations in adults be extrapolated to adolescents? J Pediatr 158: 947-952.

49. Dong XL, Liu Y, Sun Y, et al, 2011 Comparison of HbA1c and OGTT criteria to diagnose diabetes among Chinese. Exp Clin Endocrinol Diabetes 119: 366-369.
50. Lederbogen F, Hummel J, Fadenrecht C, et al, 2011 Flattened circardian cotisol rhythm in type 2 diabetes. Exp Clin Endocrinol Diabetes 9: 573-575.

51. Serio M, Tarquini B, Contini P, et al, 1968 Plasma cortisol response to insulin and circadian rhythm in diabetic subjects. Diabetes 17: 124-126.

52. Clayton RN, Raskauskiene D, Reulen RC, et al, 2011 Mortality and morbidity in Cushing's Disease over 50 Years in Stoke-on-Trent, UK: Audit and Meta-Analysis of Literature. J Clin Endocrinol Metab 96: 632-642.

53. Derijk RH, 2009 Single nucleotide polymorphisms related to HPA axis reactivity. Neuroimmunomodulation 16: 340-52.

54. Hamer M, Steptoe A, 2012 Cortisol responses to mental stress and incident hypertension in healthy men and women. J Clin Endocrinol Metab 97: E29-34.

55. Shah SH, de Lemos JA, 2009 Biomarkers and cardiovascular disease. JAMA 302: 92-93. 